\title{
Design and Optimizaton of Tidal Turbine Airfoil
}

\author{
F. Grasso
}

Published in: Journal of Aircraft, Vol. 49, no. 2, March-April 2012, pp. 636-643 


\title{
Design and Optimization of Tidal Turbine Airfoil
}

\author{
F. Grasso* \\ Energy Research Centre of the Netherlands, 1755 LE Petten, The Netherlands
}

DOI: $10.2514 / 1 . \mathrm{C} 031617$

\begin{abstract}
To increase the ratio of energy capture to the loading and, thereby, to reduce cost of energy, the use of specially tailored airfoils is needed. This work is focused on the design of an airfoil for marine application. Firstly, the requirements for this class of airfoils are illustrated and discussed with reference to the requirements for wind turbine airfoils. Then, the design approach is presented. This is a numerical optimization scheme in which a gradientbased algorithm is used, coupled with the RFOIL solver and a composite Bezier geometrical parameterization. A particularly sensitive point is the choice and implementation of constraints. A section of the present work is dedicated to address this point; particular importance is given to the cavitation phenomenon. Finally, a numerical example regarding the design of a high-efficiency hydrofoil is illustrated, and the results are compared with existing turbine airfoils, considering also the effect on turbine performance due to different airfoils.
\end{abstract}

\section{Nomenclature}

$C_{d} \quad=$ airfoil drag coefficient

$C_{d \min }=$ minimum airfoil drag coefficient

$C_{f} \quad=$ skin friction coefficient

$C_{l} \quad=$ airfoil lift coefficient

$C_{l \alpha}=$ slope of the lift curve, $\mathrm{deg}^{-1}$

$C_{l \max }=$ maximum airfoil lift coefficient

$C_{m c / 4}=$ airfoil moment coefficient referred to the quarter of chord

$C_{p}=$ mechanical power coefficient

$C_{p \max }=$ maximum mechanical power coefficient

$C_{t} \quad=$ thrust coefficient

$c \quad=$ airfoil chord, $\mathrm{m}$

$c_{p} \quad=$ pressure coefficient

$F \quad=$ objective function

$F_{\mathrm{ax}} \quad=$ axial force, $\mathrm{N}$

$g \quad=$ inequality constraints

$H \quad=$ boundary layer shape factor

$h \quad=$ equality constraints

$L / D=$ aerodynamic efficiency

$P_{\text {rated }}=$ rated power, $\mathrm{kW}$

$P_{v} \quad=$ vapour pressure, $\mathrm{Pa}$

$P_{0} \quad=$ local pressure, $\mathrm{Pa}$

$Q_{\text {start }}=$ torque at cut-in wind speed and zero rotor speed, $\mathrm{kNm}$

$q \quad=$ dynamic pressure, $\mathrm{Pa}$

$v \quad=$ water speed, $\mathrm{m} / \mathrm{s}$

$X \quad=$ design variables

$X^{L} \quad=$ lower bounds for the design variables

$X^{U} \quad=$ upper bounds for the design variables

$\alpha \quad=$ angle of attack, deg

$\lambda=$ tip speed ratio

$\sigma_{c} \quad=$ cavitation parameter

$\Omega \quad=$ rotational speed, $\mathrm{rpm}$

\section{Introduction}

D UE to the intrinsic requirements in terms of design point, offdesign capabilities, and structural properties, more and more

Presented as Paper 2011-3816 at the 29th AIAA Applied Aerodynamics Conference, Honolulu, HI, 27-30 June 2011; received 5 August 2011; accepted for publication 16 September 2011. Copyright $\odot 2011$ by Francesco Grasso. Published by the American Institute of Aeronautics and Astronautics, Inc., with permission. Copies of this paper may be made for personal or internal use, on condition that the copier pay the $\$ 10.00$ per-copy fee to the Copyright Clearance Center, Inc., 222 Rosewood Drive, Danvers, MA 01923 ; include the code 0021-8669/12 and \$10.00 in correspondence with the CCC.

*Postdoctoral Aerodynamicist, Wind Energy Unit, Rotor and Wind Farm Aerodynamics Group, Westerduinweg 3; grasso@ecn.nl. Associate Fellow AIAA. new airfoil families for wind turbines have been developed [1-4]. However, apart from some development done by Eppler [5], there are not specific studies in the literature focused on airfoils for tidal turbines.

This work is focused on the design of a tidal-turbine-dedicated airfoil by using numerical optimization. In the next section, the requirements for this class of airfoils are presented; then, details about the design approach and its implementation are provided. Finally, the development of the new airfoil is described, and the results are discussed.

\section{Airfoils for Tidal Turbines}

In the present section, the requirements for tidal turbine airfoils are illustrated by using wind turbine airfoil requirements as reference. A complete discussion about the requirements for wind turbine airfoils can be found in previous work by the present author [6].

\section{A. Structural Requirements}

Airfoil characteristics include both aerodynamic and structural requirements. For the outer part of the blade, the most important parameters, from the structural point of view, are the maximum airfoil thickness and the chordwise location of the maximum thickness. The thickness of the profile must be able to accommodate the structure necessary to ensure the blade strength and stiffness. Depending of the class of the wind turbine, certain values for the thickness along the blade can be expected, and this fact introduces a first indication for the design problem. The location of the maximum thickness along the chord is also important; when an airfoil is designed, the other airfoils along the blade should be considered to guarantee constructive compatibility. This means that, to allow the spar passing through the blade, the chordwise position of the thickness should be similar for the complete blade.

\section{B. Aerodynamic Requirements}

From the aerodynamic point of view, the most important parameter for the tip region is the aerodynamic efficiency $(L / D)$. To obtain good turbine performance, the aerodynamic efficiency should be as high as possible, but, at the same time, other considerations should be taken into account.

\section{Cavitation}

The biggest difference between tidal and wind turbine airfoils is connected with the cavitation phenomenon. Cavitation consists in the formation of vapor bubbles of a flowing liquid in a region where the pressure of the liquid falls below its vapor pressure. Cavitation is usually divided into two classes of behavior: inertial (or transient) cavitation and noninertial cavitation. Inertial cavitation is the process 
where a void or bubble in a liquid rapidly collapses, producing a shock wave. Such cavitation often occurs in control valves, pumps, propellers, impellers, and the vascular tissues of plants. Noninertial cavitation is the process in which a bubble in a fluid is forced to oscillate in size or shape due to some form of energy input, such as an acoustic field. From the aerodynamic point of view, the inertial cavitation is undesirable because the shock waves formed are strong enough to significantly damage moving parts, so it should be take into account during the design (see Figs. $\underline{1}$ and 2 ). The cavitation parameter $\left(\sigma_{c}\right)$ is defined as

$$
\sigma_{c}=\frac{p_{0}-p_{v}}{q}
$$

where $P_{v}$, mainly dependent on water temperature, is the vapour pressure, $P_{0}$ is the local pressure, and $q$ is the dynamic pressure. If the local pressure coefficient on the suction side is larger (in absolute value) than $\sigma_{c}$, cavitation occurs.

\section{Stall Behavior and Max Lift Coefficient}

Some of the existing airfoils for wind turbines also have a high value of the maximum lift coefficient $\left(C_{l \max }\right)$ and a relatively high value for the design lift coefficient $\left(C_{l}\right)$; this means that, for a certain load, a smaller chord is necessary. A lower chord in the outboard sections also reduces weight. For marine applications, the stall behavior is more important than the $C_{l \max }$. So, the transition and the separation should move gradually when the angle of attack increases.

A high $C_{l}$ value (and lower associated chord $c$ ) reduces the amplitude of load fluctuations resulting from wind gusts and fatigue loads. In water, the turbulence is lower; this means that problems connected with fatigue have lower priority.

Also, because of gusts, in wind turbines the local angle of attack for the single airfoil can suddenly change and be in prestall or stall zone. Because of this, it is important to have an angle of attack range

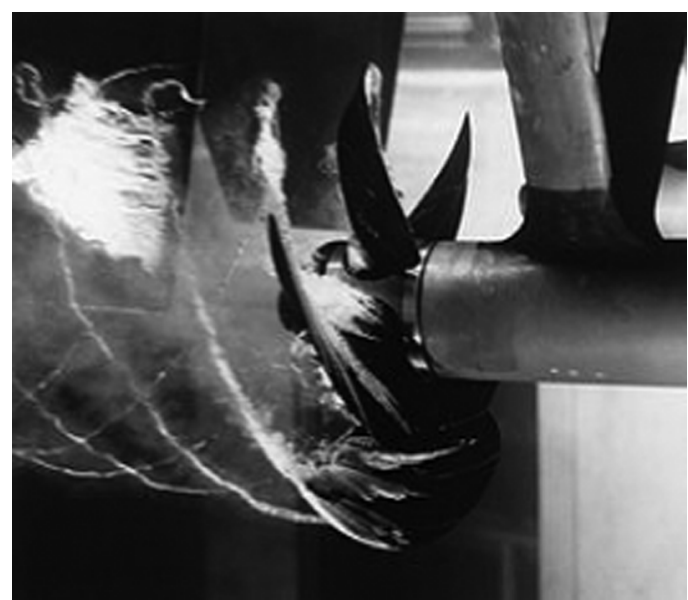

Fig. 1 Cavitating propeller model in a water tunnel experiment.

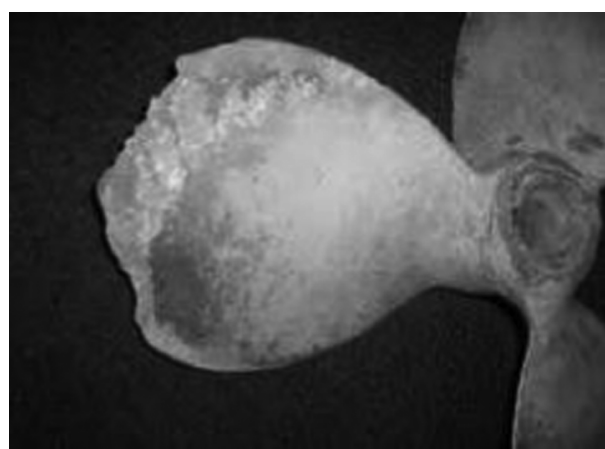

Fig. 2 Damage on propeller due to cavitation. between the design angle of attack and the one for which noticeable separation occurs on the airfoil. For tidal turbines, especially if the turbine is a stall-regulated turbine, it is convenient to reduce this margin to few degrees in order to use a stall mechanism to stop the turbine as soon the turbine overcomes the design condition.

\section{Robustness to Roughnes.}

Another important consideration is related with the sensitivity of the airfoil to the roughness. An airfoil with a large laminar flow extension will be very efficient in "clean" conditions, but very bad in case of "dirty" conditions. A large value for the leading edge can improve this aspect, and, at the same time, it can help to avoid cavitation by preventing rapid expansions.

\section{Blade Torsion}

The moment coefficient $\left(C_{m c / 4}\right)$ should be taken into account because large values of moment coefficient will give higher torsion moment on the blade. For tidal turbines, however, the aspect ratio is lower than for wind turbines; this means that the blade is more rigid regarding torsion deformation, so the blade torsion does not play a crucial role in the design process.

\section{Numerical Optimization Approach}

To design airfoils, several methodologies can be used. A very popular approach is the inverse design technique, proposed by Lighthill [7] and widely developed by Eppler [5], Eppler and Somers [8], Drela [9], and Drela and Giles [10]. The basic principle of this design method is that the pressure coefficient on the airfoil surface is prescribed, and the airfoil geometry is created; by iteratively modifying the pressure distribution on the airfoil surface, the designer can generate the geometry of an airfoil that satisfies the requirements. Despite its large use, there are several disadvantages associated with this technique; the most evident is that it is very difficult to take into account multiple requirements at the same time, especially when they concern different disciplines.

A valid alternative to solve this problem is the usage of multidisciplinary design optimization (MDO) approach. In the most general sense, numerical optimization $[11,12]$ solves the nonlinear, constrained problem to find the set of design variables, $X_{i}, i=1$, and $N$, contained in vector $\boldsymbol{X}$, that will

$$
\text { Minimize } F(X)
$$

subject to

$$
\begin{gathered}
g_{j}(X) \leq 0 \quad j=1, M \\
h_{k}(X)=0 \quad k=1, L \\
X_{i}^{L} \leq X_{i} \leq X_{i}^{U} \quad i=1, N
\end{gathered}
$$

Equation (2) defines the objective function, which depends on the values of the design variables, $\boldsymbol{X}$. Equations (3) and (4) are inequality and equality constraints, respectively [equality constraints can be written as inequality constraints and included in Eq. (3)], and Eq. ()ㅡㄹ defines the region of search for the minimum. The bounds defined for each degree of freedom by Eq. (5) are referred to side constraints.

\section{A. Geometry Description}

One of the most important ingredients in numerical optimization is the choice of design variables and the parameterization of our system in using these variables. To reduce the number of necessary parameters to take into account to describe the airfoil's shape, but without loss of information about the geometrical characteristics of the airfoil, several mathematical formulations were proposed in literature [13]. In the present work, a composite third-order Bezier is used. Basically, the airfoil is divided into four parts and, for each part, 


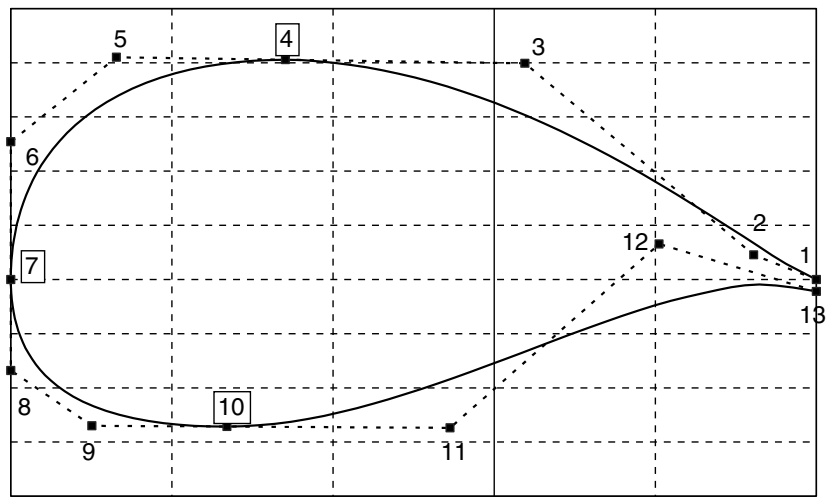

Fig. 3 Geometry parameterization example.

a third-order Bezier curve is used to describe the geometry (Fig. 3). The advantage of this choice is the possibility of conjugating the properties of Bezier functions in terms of regularity of the curve and easy usage, with a piecewise structure that allows also local modifications to the geometry. The complete description can be found in previous work by the present author [14].

\section{B. Optimization Algorithm}

The choice of optimization algorithm is very important because the final results are usually dependent on the specific algorithm in terms of accuracy and local minima sensitivity. Evolutionary algorithms are less sensitive to local minima; however, they are time consuming, and constraints have to be included as a penalty term to the objective function. On the other hand, gradient-based algorithms can lack in global optimality but allow multiple constraints and are more robust, especially for problems in which a large number of constraints are prescribed. In this investigation, an advanced sequential quadratic programming gradient-based algorithm [15] is implemented, and the gradients are approximated by finite differences.

\section{Objective Function Evaluation}

Because the optimization process requires many evaluations of the objective function and the constraints before an optimum design is obtained, the computational costs, as well as the accuracy of the results, cannot be neglected. Here, the RFOIL [16] numerical code is used. RFOIL is a modified version of XFOIL [17], featuring an improved prediction around the maximum lift coefficient and capabilities of predicting the effect of rotation on airfoil characteristics. Regarding the maximum lift in particular, numerical stability improvements were obtained by using the Schlichting [18] velocity profiles for the turbulent boundary layer, instead of Swafford's [19]. Furthermore, the shear lag coefficient in Green's lag entrainment equation of the turbulent boundary layer model was adjusted, and deviation from the equilibrium flow has been coupled to the shape factor of the boundary layer. Figures 4 and $\underline{5}$ illustrate a comparison with experimental data [20] for the NACA- $63_{3} 418$ airfoil. The Reynolds number is 6 million and the transition is free.

It should be noted that the RFOIL prediction for the stall region is well described and very close to the experimental data; in XFOIL results, only the deviation from the linear zone is described but not the stall. For the drag curve, XFOIL and RFOIL are very close to each other for small values of $C_{l}$, but, for high $C_{l}$, XFOIL is under

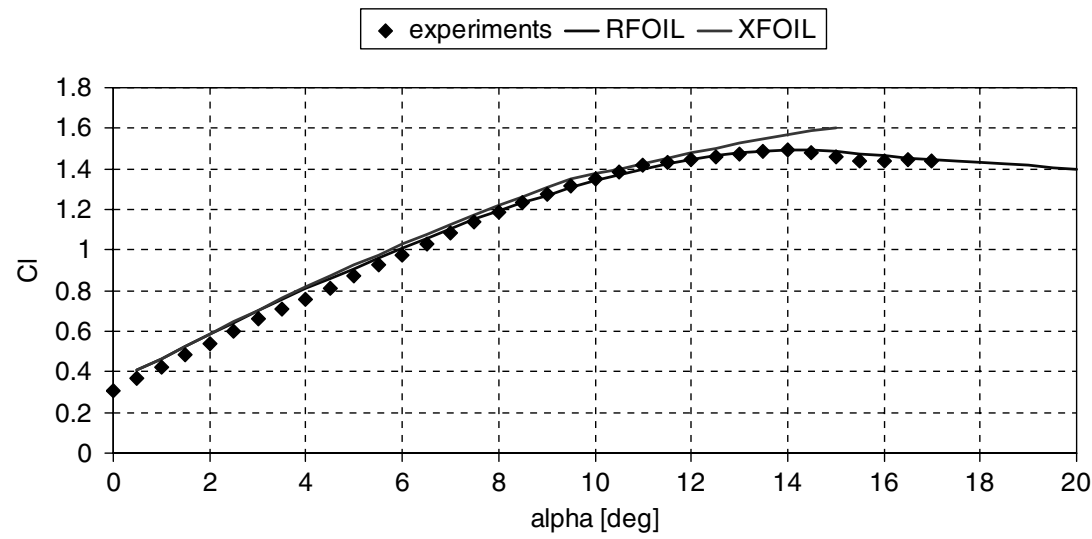

Fig. 4 Lift curve for the NACA-63 418 airfoil; comparison between XFOIL and RFOIL with experiments by Abbot and Von Droenhoff [20]. Reynolds number of $6 \times 10^{6}$ and free transition.

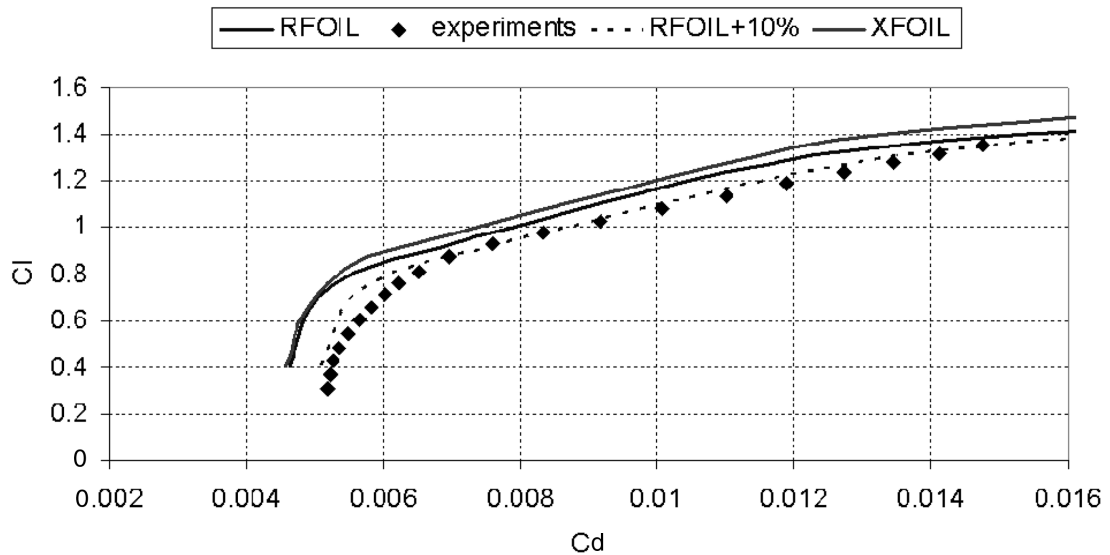

Fig. 5 Drag curve for the NACA-63 418 airfoil; comparison between XFOIL and RFOIL with experiments Abbot and Von Droenhoff [20]. Reynolds number of $6 \times 10^{6}$ and free transition. 


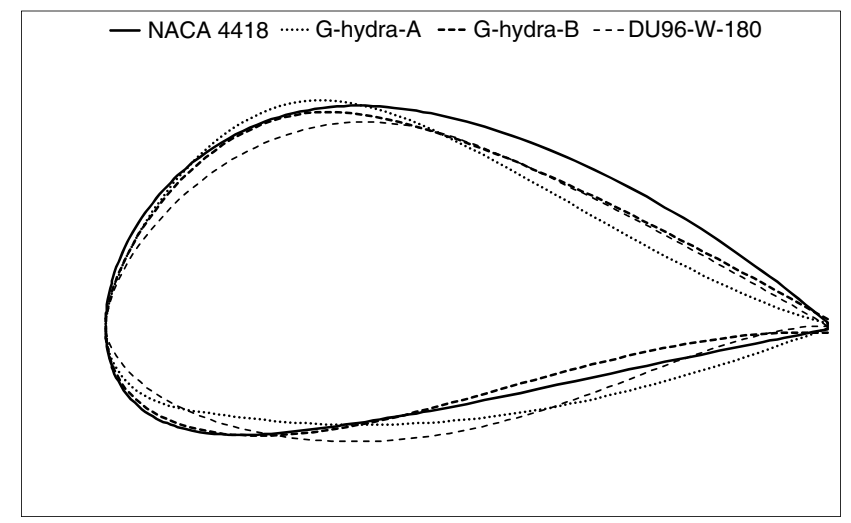

Fig. 6 G-hydra-A and G-hydra-B airfoils compared with NACA 4418 and DU96-W-180 geometries.

predicting. In van Rooij [16], a additional drag of $10 \%$ is suggested to correct the RFOIL data; by adding this factor, a very good agreement is also found for the drag coefficient. To have more realistic predictions, this $10 \%$ drag penalty is added during the optimization process and for all the numerical analyses.

\section{Design of a New Airfoil for Tidal Turbines}

The design of a new airfoil is presented in this section. A stallregulated tidal turbine is chosen as reference; the Reynolds number is $3 \times 10^{6}$, and the airfoil is designed to maximize the aerodynamic efficiency at $7 \mathrm{deg}$ of angle of attack. The same airfoil is used for all the blade.

The NACA0012 airfoil was used as baseline for the optimization. The purpose of this choice is to have a starting point for the design process as far as possible from potential local solutions and, in this way, have more confidence on the optimality of the solution.

\section{A. Geometrical Constraints}

A minimum value of $18 \%$ for the airfoil thickness is prescribed. As consequence, it should be noted that, because of the $12 \%$ thickness, the baseline is even out of the feasible domain. The trailing edge thickness can change during the design, allowing the algorithm to find the best value; however, a minimum value of $0.25 \%$ of the chord is required to ensure airfoil's feasibility from a manufacturing point of view.

One of the problems outlined in the preceding sections is the insensitivity for the roughness and the need to have a smooth stall with gradual transition and separation. By using the results of ESDU

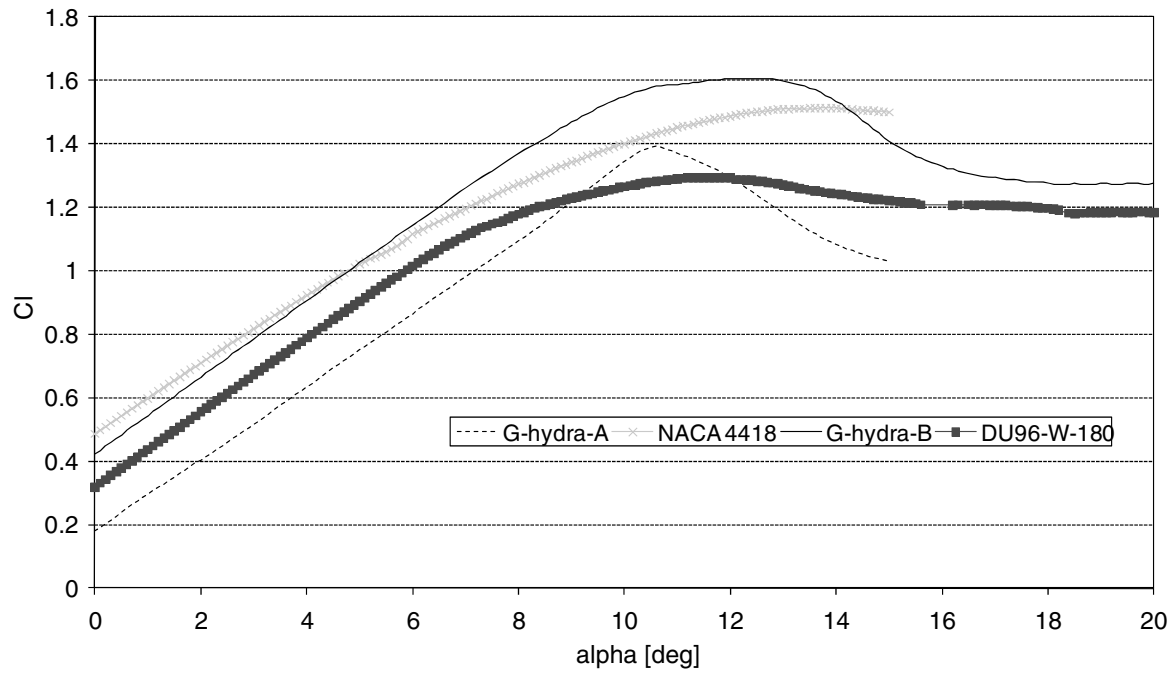

Fig. 7 Lift coefficient curve; G-hydra-A and G-hydra-B airfoils compared with NACA 4418 and DU96-W-180 geometries. Reynolds number of $3 \times 10^{6}$, free transition, and RFOIL predictions.

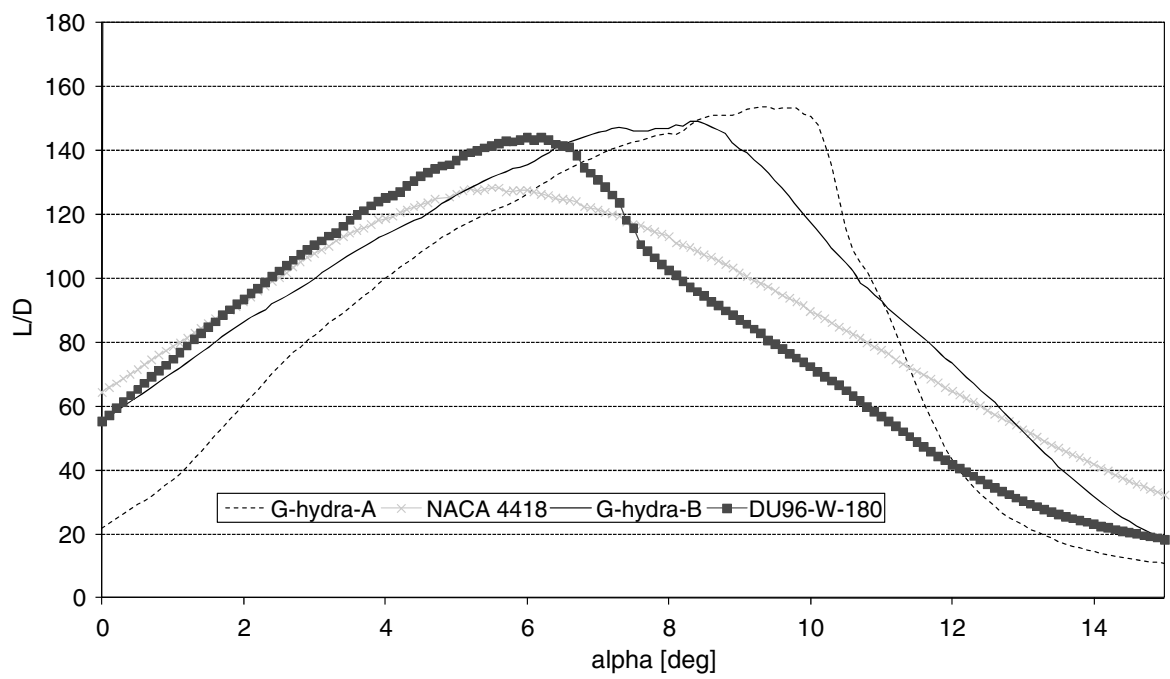

Fig. 8 Efficiency curve; G-hydra-A and G-hydra-B airfoils compared with NACA 4418 and DU96-W-180 geometries. Reynolds number of $3 \times 10^{6}$, free transition, and RFOIL predictions. 


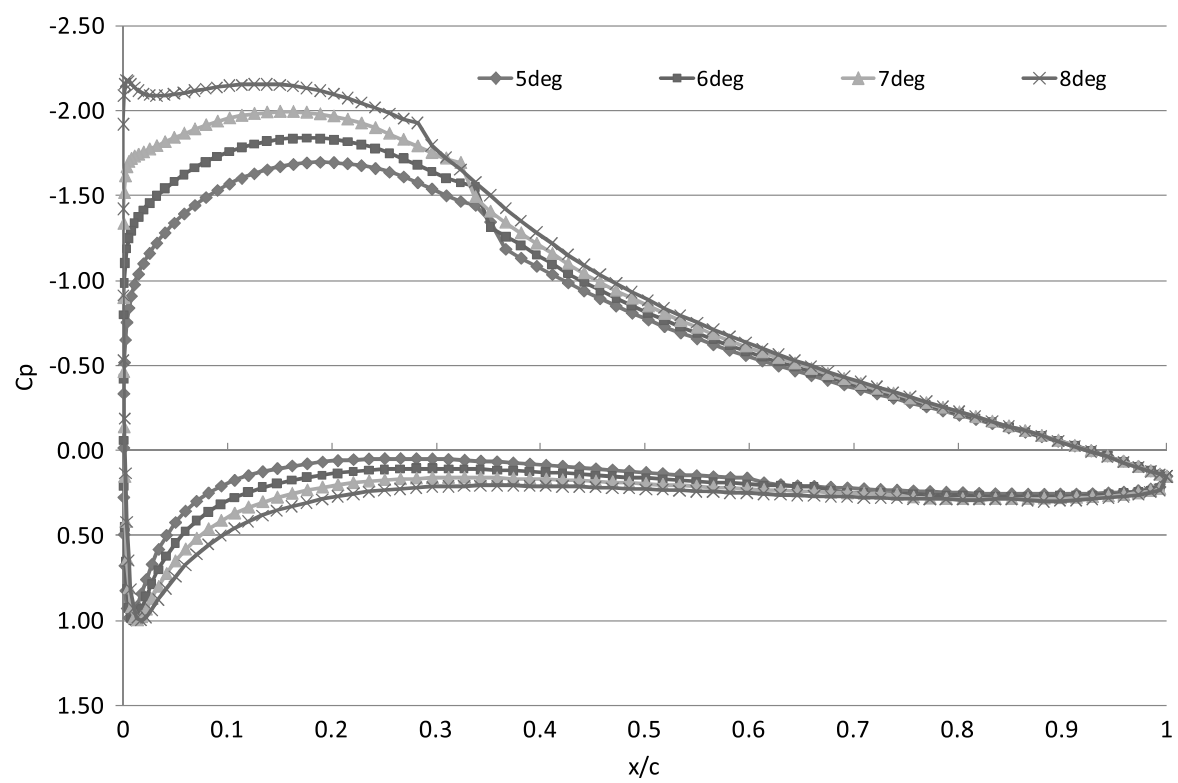

Fig. 9 Pressure coefficient distribution for G-hydra-B airfoil. Reynolds number of $3 \times 10^{6}$, free transition, and RFOIL predictions.

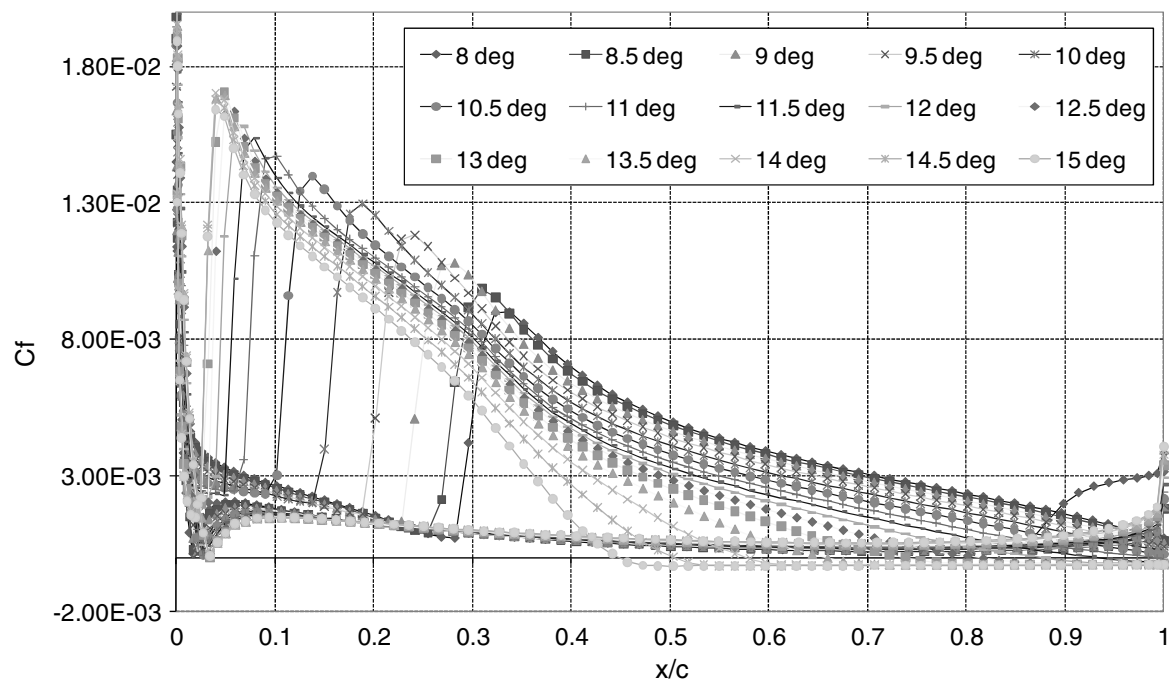

Fig. 10 Skin friction coefficient distribution for G-hydra-B airfoil. Reynolds number of $3 \times 10^{6}$, free transition, and RFOIL predictions.

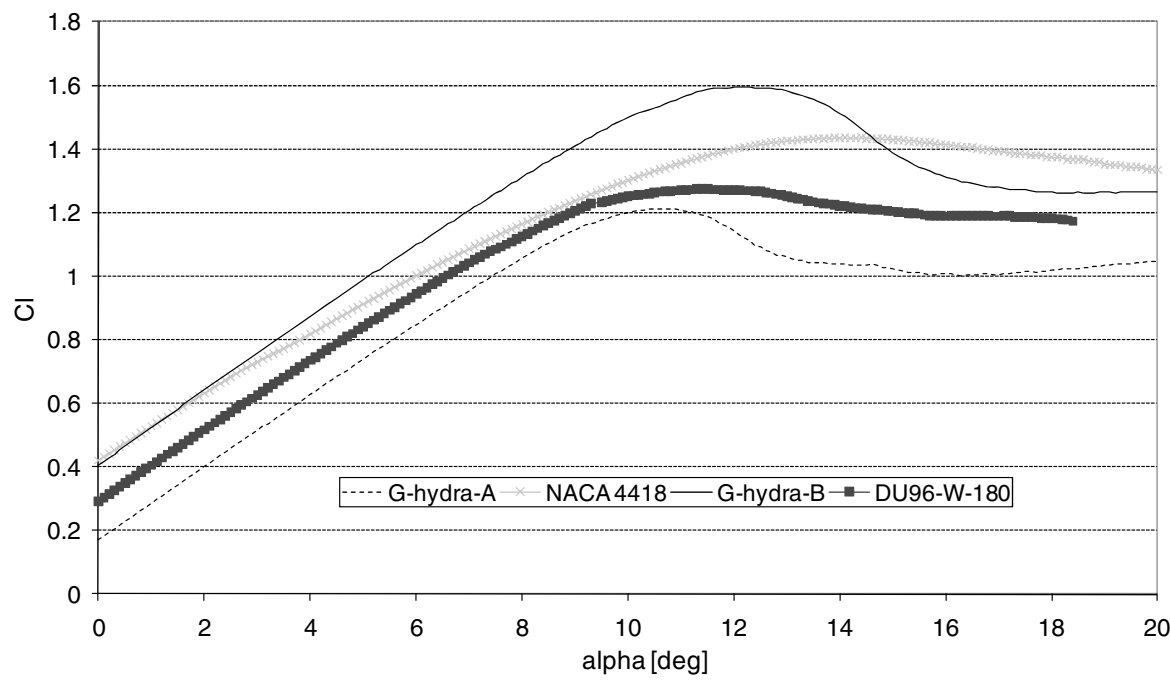

Fig. 11 Lift curve; G-hydra-A and G-hydra-B airfoils compared with NACA 4418 and DU96-W-180 geometries. Reynolds number of $3 \times 10^{6}$, fixed transition, and RFOIL predictions. 


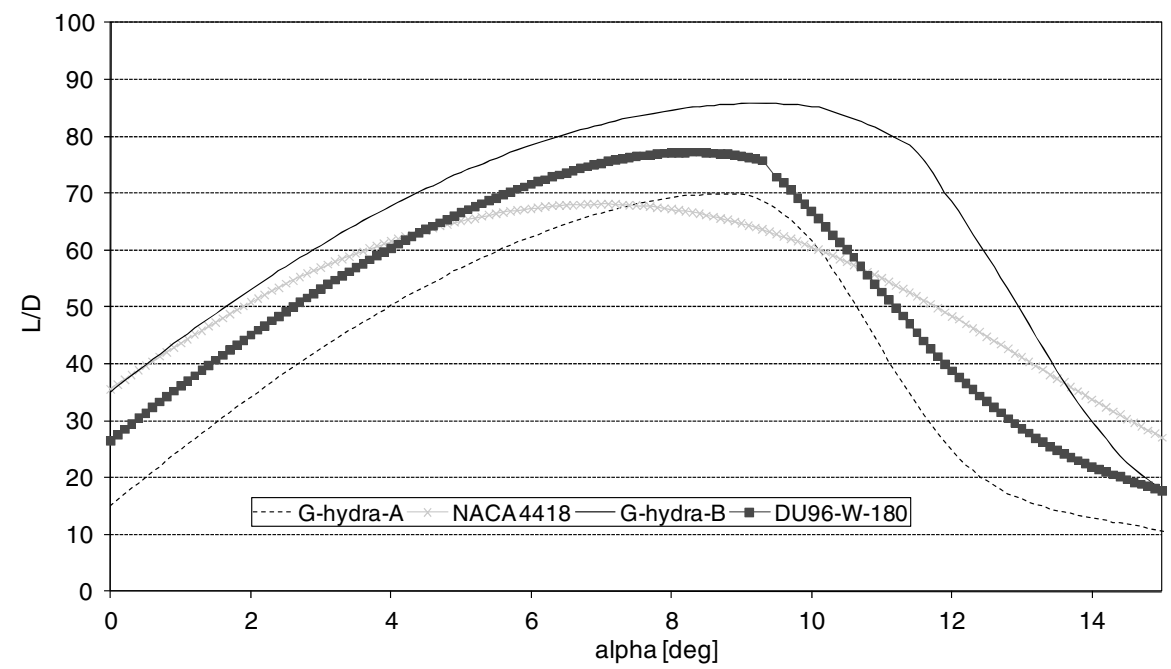

Fig. 12 Efficiency curve; G-hydra-A and G-hydra-B airfoils compared with NACA 4418 and DU96-W-180 geometries. Reynolds number of $3 \times 10^{6}$, fixed transition, and RFOIL predictions.

[21], a minimum value for the ordinate at $x / c$ equal to $0.0125 c$ can be selected to ensure a trailing edge separation. From this parameter, a minimum leading edge radius of $0.0155 c$ can be assigned.

\section{B. Aerodynamic Constraints}

To avoid the possibility of abrupt stall and not gradual evolution in transition location, the design is performed by fixing transition at $0.01 c$ on the suction side and $0.1 c$ on the pressure side. However, to check the effect of the imposed transition on the final geometry, the design process has been performed twice (in free and fixed transition), and the results are discussed, also considering free transition condition.

As discussed in section II.B, preventing cavitation is the main issue for marine applications. In the present work, the pressure coefficient $\left(c_{p}\right)$ distribution is calculated for each geometry, and the expansion peak is compared with the cavitation parameter. A water temperature of $10^{\circ} \mathrm{C}$, a water depth equal to $1 \mathrm{~m}$, and a local velocity of $10.5 \mathrm{~m} / \mathrm{s}$ are assumed; from these values, a value equal to 2 for the cavitation parameter is calculated.

\section{Results}

\section{Airfoil Performance}

Two airfoils have been designed: the G-hydra-A, obtained in free transition conditions, and the G-hydra-B, obtained in fixed transition conditions. Figure 6 shows the comparison between these new airfoils, the NACA $\overline{4} 418$ airfoil, and the DU96-w-180 airfoil.

In Figs. 7 and $\underline{8}$, the aerodynamic characteristics are compared. Both airfoils improve the aerodynamic efficiency and respect the set of constraints. The main difference between G-hydra-A and Ghydra-B geometries is in the aft part of the airfoil. The G-hydra-A airfoil is less cambered; because of this, the $C_{m c / 4}$ (in absolute value) as well as the lift curve are lower. Looking at the stall, the

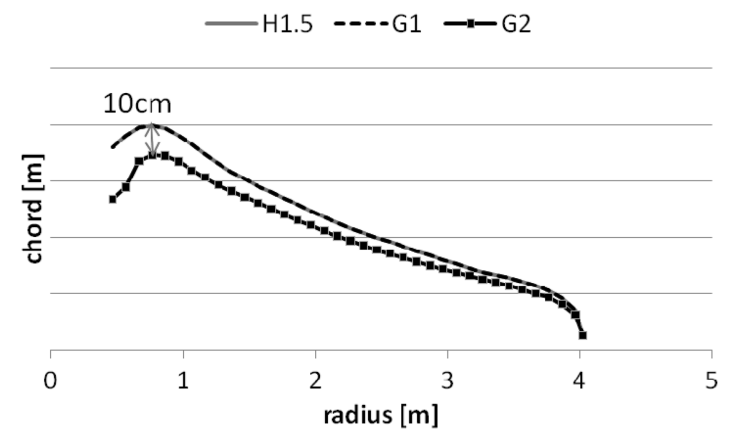

Fig. 13 Comparison between chord distributions for different blade geometries. characteristics of the G-hydra-B airfoil are quite good in terms of quality of the stall and $C_{l \max }$. Because of the concave shape on the suction side of the G-hydra-A airfoil, the lift suddenly decreases as well as the efficiency, after the maximum is reached. Considering the G-hydra-B airfoil, there is some margin between design asset and stall but not so long as for the NACA 4418. As mentioned in the introductory paragraph of section IV, a stall-regulated turbine is used as reference; for these turbines, a little margin between design and stall conditions can be an advantage because it ensures that, from the design condition, the break mechanism (the stall) starts to work before the turbine stays too long in an off-design condition. Another good characteristic of the G-hydra-B airfoil is that the linear part of the lift curve is quite extended compared with the reference geometries.

Figure 9 shows the pressure distribution for the G-hydra-B airfoil around the design condition. It should be noticed that the constraint about cavitation is respected, and expansion peaks appear only for

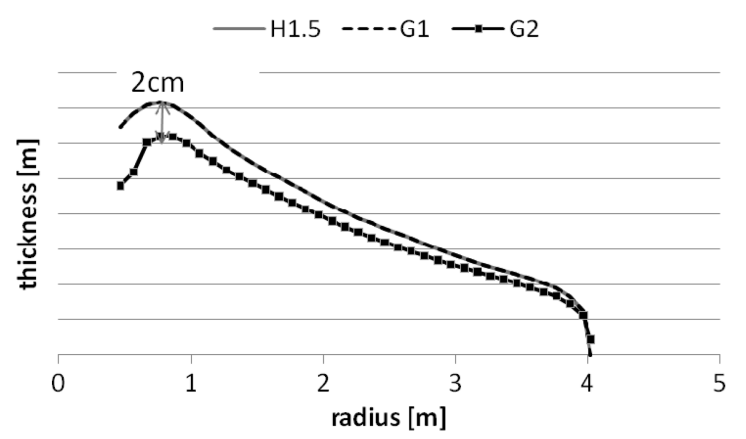

Fig. 14 Comparison between thickness distributions for different blade geometries.

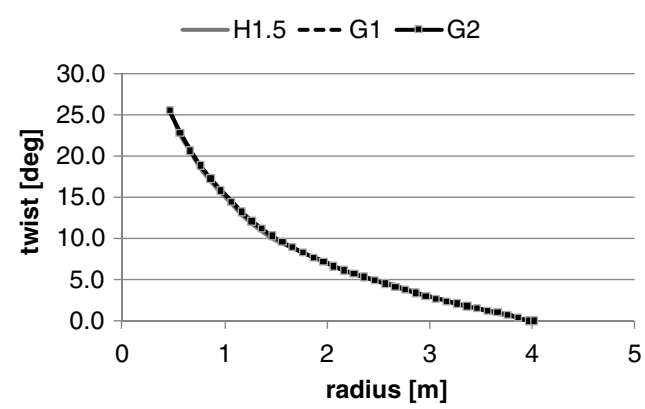

Fig. 15 Comparison between twist distributions for different blade geometries. 
Table 1 Comparison between turbine performance

\begin{tabular}{lccc}
\hline \hline & $\mathrm{H} 1.5$ & $\mathrm{G} 1$ & $\mathrm{G} 2$ \\
\hline Yield, $\mathrm{Gwh} / \mathrm{yr}$ & 0.185 & 0.190 & 0.189 \\
$P_{\text {rated }}, \mathrm{kW}$ & 90.4 & 95.5 & 94.1 \\
$U_{\text {rated }}, \mathrm{m} / \mathrm{s}$ & 2.00 & 2.00 & 2.00 \\
$C_{P \max }$ & 0.4821 & 0.4853 & 0.4865 \\
$\lambda_{o}$ & 7.000 & 7.000 & 7.000 \\
$Q_{\text {start }}, \mathrm{kNm}$ & 2.196 & 2.722 & 2.914 \\
\hline \hline
\end{tabular}

higher values of angles of attack. To check the gradual evolution of the stall, the skin friction coefficient $C_{f}$ has been considered (see Fig. 10).

The comparisons have been also performed by imposing the location of the transition at $5 \%$ of the chord, both on the suction and the pressure sides.

Figure 11 shows the comparison in terms of lift curve. Looking at the extent of the linear part, the value of the maximum lift coefficient and the quality of the stall, the lift curve of the G-hydra-B airfoil is almost unchanged in fixed transition conditions. Because of the imposed transition, the aerodynamic efficiency decreases for all the airfoils (Fig. 12); however, the losses of the G-hydra-B airfoil are limited, especially if compared with the G-hydra-A airfoil.

\section{Turbine Performance}

To have a complete overview on the new airfoil's performance, the effects in terms of turbine performance have been investigated. A blade for stall-regulated turbine has been used as reference (referred in the text as H1.5); the NACA4418 airfoil was installed along all the $4 \mathrm{~m}$ radius blade, designed to work at $1.5 \mathrm{~m} / \mathrm{s}$ water speed at fixed pitch angle and constant rotational speed $(\Omega=24.93 \mathrm{rpm})$.

Starting from this geometry, two new blades have been developed by adopting the G-hydra-B airfoil along the blade. In the first geometry, named G1, only the airfoil is different by keeping chord,

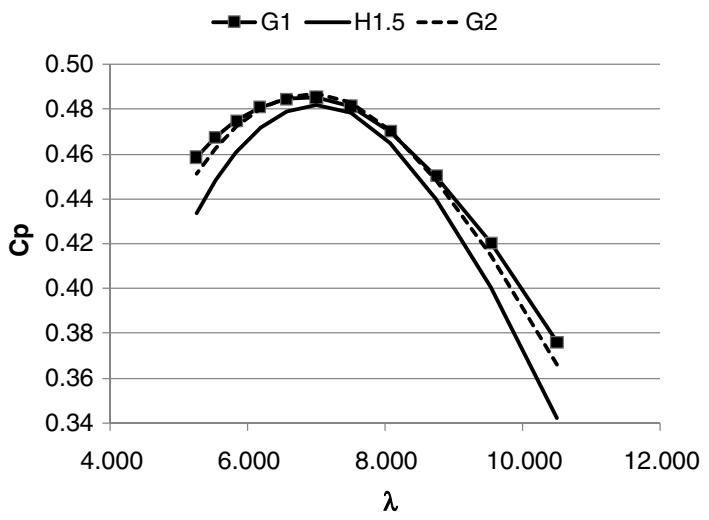

Fig. 16 Comparison between different blades. $C p-\lambda$ curve.

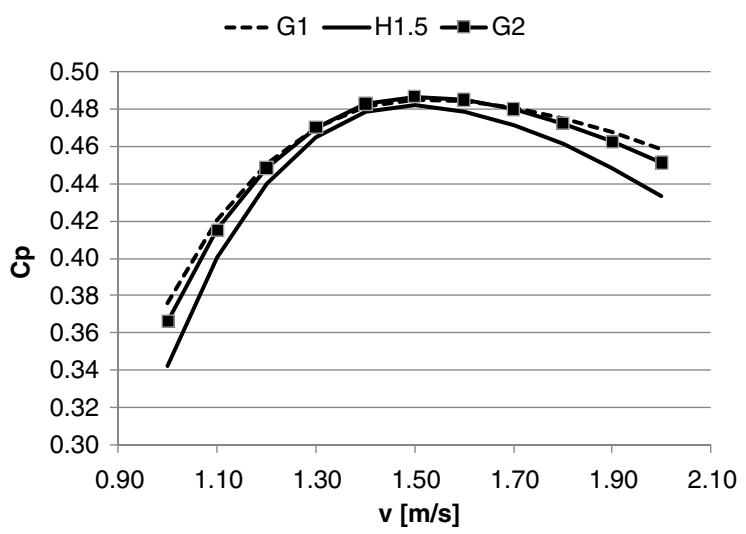

Fig. 17 Comparison between different blades. $C p-v$ curve. twist, and thickness distributions unchanged; instead, the second geometry, denoted as G2, also has new chord, twist, and thickness distributions. All the analyses and the designs have been performed by using BOT code [22] developed at the Energy Research Centre of the Netherlands by Bot. This code is based on blade element momentum theory, and it is capable of optimizing chord and twist distributions to maximize the annual energy yield.

Figures 13-15 show the comparisons between the geometries. The G1 blade and the reference configuration (H1.5) are exactly the same; the G2 blade has different chord (and so thickness) distribution but same twist distribution, despite the fact that it was redesigned from scratch. The chords of the G2 blade are smaller than the reference, allowing for the decrease in the weight and the cost connected to the material.

In terms of global performance, both $\mathrm{G} 1$ and $\mathrm{G} 2$ blades improve the yield production, as well as the power, the mechanical $C p_{\max }$ and the $Q_{\text {start }}$ (see Table 1 ). The following Figs. $\underline{16}-\underline{20}$ illustrate the

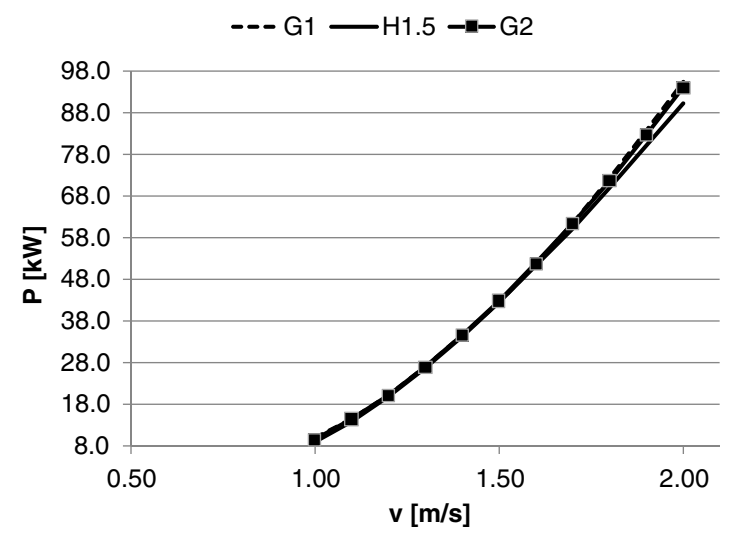

Fig. 18 Comparison between different blades. Power curve.

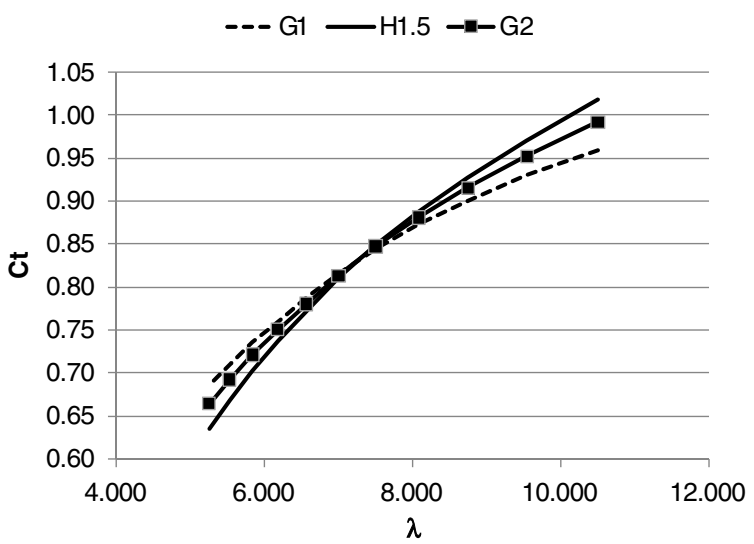

Fig. 19 Comparison between different blades. $C t-\lambda$ curve.

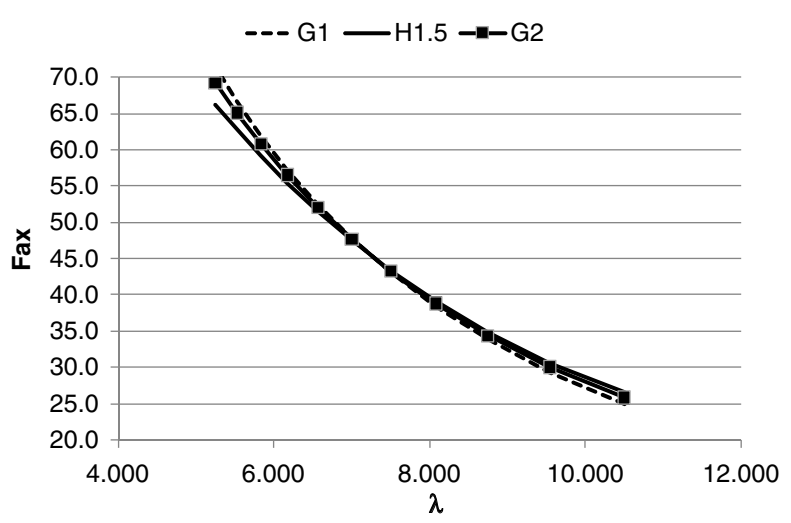

Fig. 20 Comparison between different blades. Axial force- $\lambda$ curve. 
results of comparison with the reference geometry. For both, G1 and $\mathrm{G} 2$ blades, the performance in terms of $C p-\lambda$ and $C p-v$ curves is better than the reference geometry. Also, the power curve is better.

Looking at the $C t-\lambda$ curve and the axial force, it should be noticed that the new blades are achieving a better performance for high values of $\lambda$ but not for low values. However, low $\lambda$ values correspond to working conditions (high water velocity) in which the control system is active (eventually to stop the turbine).

\section{Conclusions}

Two new airfoils for tidal turbines were designed. According to the RFOIL predictions, the results for one of them (G-hydra-B) are promising when compared with the NACA 4418 and the DU96-W180 airfoils. A good value for the efficiency was achieved with separation limited only in the stall zone and without cavitation. Because of the relatively large leading edge radius, the performances in off-design and rough conditions, as well as the stall that is quite smooth, are also good. The effects of a new airfoil have also been investigated by comparing the performance of different blades. The blades where the G-hydra-B airfoil is installed show higher values of $C_{p \max }$, annual yield production, and, in general, better performance.

Despite these good results, wind tunnel tests are recommended to validate predictions. Especially for the stall behavior, the numerical predictions and, consequently the MDO process used in this work, need to be verified.

\section{Acknowledgments}

The author would like to thank H. Snel for the precious help and suggestions offered during this work. The author would also like to thank L. Machielse and G. Schepers for providing the reference blade geometry and useful feedback.

\section{References}

[1] Tangler, J. L., and Somers, D. M., "NREL Airfoil Families for HAWT's," Proc. WINDPOWER'95, AWEA, Washington, D.C., 1995, pp. 117-123.

[2] Björk, A., "Coordinates and Calculations for the FFA-W1-xxx, FFAW2-xxx and FFA-W3-.xxx Series of Airfoils for Horizontal Axis Wind Turbines," FFA TN 1990-15, Stockholm, Sweden, 1990.

[3] Timmer, W. A., and van Rooij, R. P. J. O. M., "Summary of the Delft University Wind Turbine Dedicated Airfoils," AIAA Paper 2003-0352.

[4] Fuglsang, P., and Bak, C., "Design and Verification of the new Ris $\emptyset-A 1$ Airfoil Family for Wind Turbines," AIAA Paper 2001-0028.
[5] Eppler, R., Airfoil Design and Data, Springer-Verlag, Berlin, 1990.

[6] Grasso, F., "Usage of Numerical Optimization in Wind Turbine Airfoil Design," 28th Applied Aerodynamics Conference, AIAA Paper 20104404, Chicago, IL, 28 June-1 July 2010; also Journal of Aircraft, Vol. 48, No. 1, Jan.-Feb. 2011, pp. 248-255. doi:10.2514/1.C031089

[7] Lighthill, M. J., "A New Method of Two-Dimensional Aerodynamic Design," Reports and Memoranda, Aeronautical Research Council, 1111,1945

[8] Eppler, R., and Somers, D. M., "A Computer Program for the Design and Analysis of Low-Speed Airfoils," NASA TM-80210, 1980.

[9] Drela, M., "XFOIL: An Analysis and Design System for Low Reynolds Number Airfoils," Conference on Low Reynolds Number Airfoil Aerodynamics, Notre Dame, IN, June 1989.

[10] Drela, M., and Giles, M. B., "Viscous-Inviscid Analysis of Transonic and Low Reynolds Number Airfoils," AIAA Journal, Vol. 25, No. 10, Oct. 1987, pp. 1347-1355. doi: $10.2514 / 3.9789$

[11] Fletcher, R., Practical Methods of Optimization, Wiley, New York, 1987.

[12] Pedregal, P., Introduction to Optimization, Springer, New York, 2004, ISBN 0-387-40398-1.

[13] Samareh, J. A., "Survey of Shape Parameterization Techniques for High-Fidelity Multidisciplinary Shape Optimization," AIAA Journal, Vol. 39, No. 5, May 2001, pp. 877-884. doi: $10.2514 / 2.1391$

[14] Grasso, F., "Multi-Objective Numerical Optimization Applied to Aircraft Design," Ph.D. Thesis, Dip. Ingegneria Aerospaziale, Università di Napoli Federico II, Napoli, Italy, Dec. 2008.

[15] Dai, Y.-H., and Schittkowski, K., "A Sequential Quadratic Programming algorithm With Non-Monotone Line Search," Pacific Journal of Optimization, Vol. 4, No. 2, 2001, pp. 335-351.

[16] van Rooij, R. P. J. O. M., "Modification of the Boundary Layer Calculation in RFOIL for Improved Airfoil Stall Prediction," TU-Delft Report IW-96087R, Delft, the Netherlands, Sept. 1996.

[17] Drela, M., XFOIL 6.94 User Guide, MIT Aero \& Astro, Boston, MA, Dec. 2001

[18] Schlichting, H., Boundary Layer Theory, McGraw-Hill Inc., New York, 1987.

[19] Swafford, T. W., "Analytical Approximation of Two-Dimensional Separated Turbulent Boundary-Layer Velocity Profile," AIAA Journal, Vol. 21, No. 6, 1983, pp. 923-926. doi: $10.2514 / 3.8177$

[20] Abbott, I., and Von Doenhoff, A., "Theory of Wing Sections," Dover Publications, Inc., 1958.

[21] ESDU, "The Low-Speed Stalling Characteristics of Aerodynamically Smooth Airfoils", ESDU 66034, London, Oct. 1966.

[22] Bot, E. T. G., and Ceyhan, O., "Blade Optimization Tool, User Manual,'ECN, ECN-E--09-092, Petten, the Netherlands. 